\title{
Study on Characteristics of Heat Transfer and Flow Resistance in Random Porous Foam Metal
}

\author{
Aiqiang Chen ${ }^{1,2}$, Sizhong Gu ${ }^{1,2}$, El Achkar Georges ${ }^{1,2}$, Rachid Bennacer ${ }^{2,3}$, Bin Liu ${ }^{1,2 *}$ \\ ${ }^{1}$ Tianjin Key Laboratory of Refrigeration Technology, Tianjin University of Commerce, 300134 Tianjin, China \\ ${ }^{2}$ International Centre in Fundamental and Engineering Thermophysics, Tianjin University of Commerce, 300134 Tianjin, \\ China \\ ${ }^{3}$ LMT/ENS-Cachan/CNRS/Université Paris Saclay, 61 Avenue du Président Wilson, 94235 Cachan, France
}

\begin{abstract}
Porous foam metal has great application prospects in the field of compact heat exchangers. The characteristics of heat transfer and resistance for foam metal with random structure and different porosities $(30 \%, 50 \%, 70 \%$ and $90 \%)$ were studied by finite element method in this study. The generated foam structures can be considered as homogeneous model and has better heat exchange capacity at higher inlet flow rate, and the boundary layer can develop well along the flow direction. The open-cell foam metal structure has a uniform heat transfer perpendicular to the flow direction. The bottom plate temperature of the low-porosity structure is more uniform at low flow rates. The intermediate porosities $(50 \%$ and $70 \%)$ at high flow rates has a higher uniformity. As the porosity decreases, the internal pressure increases significantly and the pressure loss also becomes significantly larger. The corresponding optimal porosity is $57 \%, 66 \%$ and $76 \%$ at inlet flow rates of $0.001 \mathrm{~m} / \mathrm{s}, 0.01$ $\mathrm{m} / \mathrm{s}$ and $0.1 \mathrm{~m} / \mathrm{s}$, respectively.
\end{abstract}

\section{Introduction}

It is important to improve the efficiency of heat exchangers and to reduce costs of equipment maintenance by enhancing heat transfer. Methods to achieve this purpose can be divided into passive technologies [1] and active technologies [2]. The most common is rectangular straight rib, which has arealy been difficult to achieve greater heat transfer efficiency.

Metal foam can significantly reduce the volume and mass of heat exchange equipments and has great application prospects in many areas, such as multifunctional heat exchangers[3-5], cooling systems[6], high-power batteries[7], compact electronic radiators $[8][9,10]$. There are many parameters affecting the flow and heat transfer inside metal foam, so it is important to understand the mechanism of heat transfer enhancement and to balance the resistance and heat exchange capability.

Medraj, et al [11] carried on some experiments using foam metals with simple or complex structure, and found that the permeability is inversely proportional to the pore size for foam metal with complex structure, but it is opposite for foam metal with simple structure. Wang H. et al [12] presented some results about the air flow and heat transfer through tubes filled with stainless steel foam, based on which they developed two new correlations for the pressure drop through metal foams under high velocity and for Nusselt number under convective boundary condition, respectively. Bamorovat A G, et al [13] investigated the two-phase flow inside a circular copper mini tube filled with foam metal, and successfully gave new correlations of both the heat transfer coefficient and pressure drop with good agreement. Metal foam produces greater resistance to internal fluid flow, which is related with not only their characteristic parameters [14], but also the nature and phase change of the fluid $[15,16]$.

The heat transfer characteristics are mainly reflected by the convective heat transfer within the foam metal. Nazari et al. [17] investigated experimentally the forced convective heat transfer of $\mathrm{Al}_{2} \mathrm{O}_{3} /$ Water nanofluid through a circular tube filled with a metal foam, and shown a direct relationship between the Nusselt number and the volume fraction of $\mathrm{Al}_{2} \mathrm{O}_{3}$. The data also indicate a significant improvement in the heat transfer rate at the cost of a

\footnotetext{
*Corresponding author: lbtjcu@tjcu.edu.cn
} 
pressure drop increase. Mancin et al $[18,19]$ studied the heat transfer and pressure drop inside aluminum foam with different parameters, and the results show that heat transfer coefficient increases as the pore density increases. Al-Athel, et al. [20] gave a detailed approach to create a detailed and accurate 3D metal foam model, and then provided more insight into the coupled behavior of metal foam heat sinks.

Lu, et al. [21] presented an analytical study on the forced convection heat transfer characteristics in pipes filled high porosity open-cell metal-foam. The results show that the pore size and porosity of metal-foams play important roles on overall heat transfer performance and the metal-foam can dramatically enhance the heat transfer at the expense of higher pressure drop. Mahjoob et al [22] found that the performance will be improved substantially when a metal foam is inserted in the tube/channel, and introduced a performance factor including the effects of both heat transfer rate and pressure drop. Some other studies also proved that foam material has better heat transfer performance than conventional fin arrays [23, 24].

There are two main concerns on the convective heat transfer inside metal foam: resistance characteristics and heat transfer characteristics. Foam metal with low porosity can improve the convective heat transfer coefficient, but internal resistance increase observably. In this study, we generated a porous model with random structure and conducted a simulation with COMSOL on the forced convection heat transfer inside. The optimal solutions were obtained in the simulation range by focusing on the heat transfer capacity, the temperature of base plate and resistance characteristics.

\section{Analysis and modelling}

\subsection{Generation of metal foam model}

The porous model we used is foam type of voxel structure, the pores of which are almost entirely open. It is generated as following process: (1) Gaussian random function is wrote by MATLAB language with given standard deviation, mathematical expectation et al., which obeys a normal distribution as we hoped. (2)The data point coordinates and function values generated (VTK files) are visualized with Paraview (Version 5.5.1, US). (3) Suitable porous structures are obtained by adjusting the thresholds to filter out some of the data.

The porosities of cross-sections at different locations are verified to ensure the homogeneity of the structure (density, thermal conductivity, etc.). Fig. 1 shows the real porosity at different sections of two models, the porosity of which is setted to $50 \%$ and $90 \%$, respectively. It is easy to note that the actual value is highly consistent with the expected value, so we can regarded the generated structure as homogeneous.

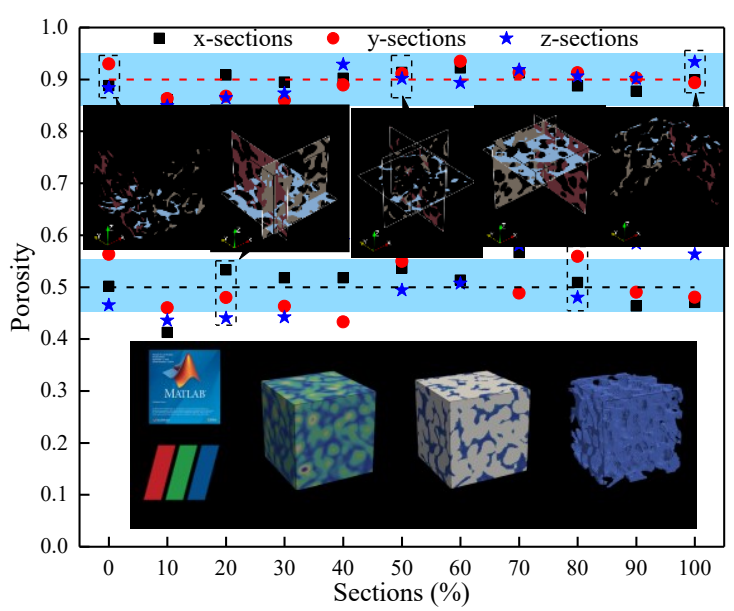

Fig. 1. Porous structure generation and verification for their homogeneity.

\subsection{Geometric model and physics description}

We mainly focus on the heat transfer and flow characteristics inside metal foam with random structure in this study, therefore, the setting of boundary condition and physical property parameter are based on but different from what really exists in the real world. The heat flux density of heating plate is constant and setted to $5 \times 10^{5}$ $\mathrm{W} / \mathrm{m}^{2}$. The length of the heating plate is consistent with that of the porous foam structure as shown in Fig. 2. The parameters of foam metal are shown in Table 1.

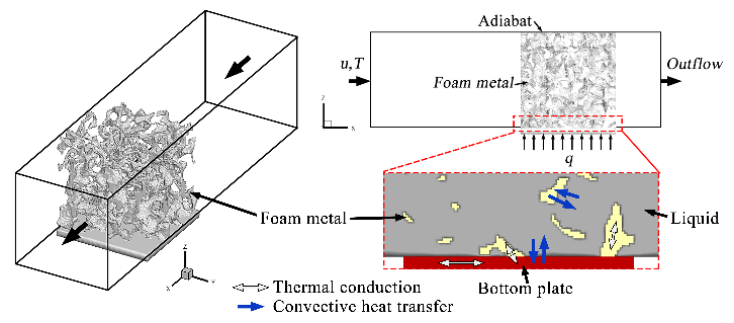

Fig. 2. Geometric model and physics configuration.

Table 1. Geometric parameters of the foam structure.

\begin{tabular}{|c|c|c|c|c|}
\hline Porosity & $\mathbf{3 0 \%}$ & $\mathbf{5 0 \%}$ & $\mathbf{7 0 \%}$ & $\mathbf{9 0 \%}$ \\
\hline $\begin{array}{c}\text { Surface area } \\
\left(\mathrm{mm}^{2}\right)\end{array}$ & 17743 & 21180 & 20409 & 12449 \\
\hline $\begin{array}{c}\text { Area in contact } \\
\text { with plate }\left(\mathrm{mm}^{2}\right)\end{array}$ & 650.7 & 481.4 & 296.7 & 105.1 \\
\hline $\begin{array}{c}\text { Specific surface } \\
\text { area }\left(\mathrm{mm}^{2} / \mathrm{mm}^{3}\right)\end{array}$ & 0.94 & 1.57 & 2.49 & 4.53 \\
\hline $\begin{array}{c}\text { Average pore } \\
\text { diameter }(\mathrm{mm})\end{array}$ & 1.82 & 2.55 & 3.68 & 7.79 \\
\hline
\end{tabular}

To simplify the research, the foam metal and base plate share the same material. It is assumed that no phase change occurs in the selected liquid and solid, and their thermal properties not change with time. The properties of fluid and solid are shown in Table 2 . 
Table 2. The properties of fluid and solid

\begin{tabular}{|l|c|c|c|}
\hline Material & $\begin{array}{c}\boldsymbol{c}_{\boldsymbol{p}} \\
(\mathbf{J} / \mathbf{( k g} \cdot \mathbf{K}))\end{array}$ & $\begin{array}{c}\boldsymbol{\rho} \\
\left(\mathbf{k g} / \mathbf{m}^{\mathbf{3}}\right)\end{array}$ & $\begin{array}{c}\boldsymbol{\lambda} \\
(\mathbf{W} / \mathbf{m} \cdot \mathbf{K})\end{array}$ \\
\hline Fluid & 4180 & 1000 & 0.599 \\
\hline Foam & 900 & 2700 & 238 \\
\hline Plate & 900 & 2700 & 238 \\
\hline
\end{tabular}

\subsection{Numerical method}

Some assumptions are made as follows: (1) radiative heat transfer is ignore throughout the process [25]; (2) the fluid is incompressible; (3) the thermal contact resistance between the foam metal and the bottom plate is negligible. The equations for laminar flow in three-dimensions are written according to the following formulation, with continuity equation:

$$
\rho \nabla \cdot(\boldsymbol{u})=0
$$

Momentum equation[26, 27]:

$$
\rho(\boldsymbol{u} \cdot \nabla) \boldsymbol{u}=\nabla \cdot\left[-p \boldsymbol{I}+\mu\left(\nabla \boldsymbol{u}+(\nabla \boldsymbol{u})^{T}\right)\right]
$$

Energy equation:

$$
\rho c_{p} \boldsymbol{u} \cdot \nabla T+\nabla \cdot(-\lambda \nabla T)=Q
$$

The boundary conditions are as follows.

Inlet boundary:

$$
\boldsymbol{u}=\text { const } ; \quad T_{0}=293.15 \mathrm{~K}
$$

Bottom boundary of base plate:

$$
\boldsymbol{n} \cdot \boldsymbol{q}=5 \times 10^{5} \mathrm{~W} / \mathrm{m}^{2}
$$

Outlet boundary:

$$
p_{0}=0 ;-\boldsymbol{n} \cdot \boldsymbol{q}=0
$$

Other boundary:

$$
\boldsymbol{u}=0 ;-\boldsymbol{n} \cdot \boldsymbol{q}=0
$$

\section{Results and discussion}

\subsection{Heat transfer}

Fig. 3 shows the evolutions of average temperatures at cross-sections with porosity of $70 \%$, which is perpendicular to Z-direction. The average temperatures of different sections become smaller gradually with increasing height and achieve a relative stable value. The $\mathrm{Z}$ coordinate of cross-section, where the temperature reaches a steady state, raises gradually with the decrease of inlet flow rate.

The coordinates are $21 \mathrm{~mm}, 12 \mathrm{~mm}$ and $3 \mathrm{~mm}$, respectively, when the inlet flow rate is $0.001 \mathrm{~m} / \mathrm{s}, 0.01$ $\mathrm{m} / \mathrm{s}$, and $0.1 \mathrm{~m} / \mathrm{s}$. Foam metal has better heat transfer capacity at higher inlet flow rate. There is a temperature boundary layer existing in the skeleton, and its thickness is gradually reduced with increasing inlet flow velocity resulting in a better developed boundary layer along the flow direction.

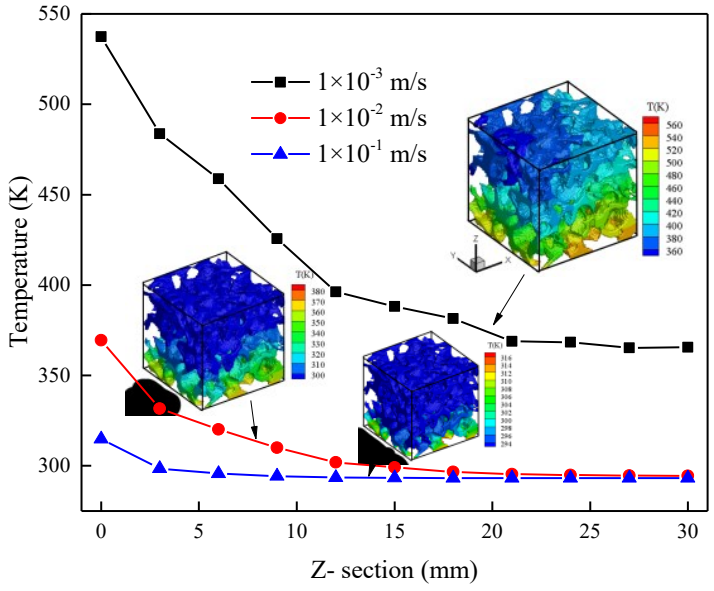

Fig. 3. Average temperature of Z-direction cross-section (Porosity: 70\%).

Fig. 4 shows the average temperatures of different YZsections and XZ-sections of bottom plate taking foam metal with a porosity of $70 \%$ as an example. The average temperature of the bottom plate is $371.51 \mathrm{~K}$ under the inlet flow velocity of $0.01 \mathrm{~m} / \mathrm{s}$. The average temperatures of YZ-sections, which is perpendicular to the flow direction, distributed around the average temperature. However, the random structure of foam metal lead to remarkable differences on the heat transfer at different sections along flow directions. The random structure improves heat transfer performance by destroying boundary layer, but increases temperature inhomogeneity in the direction perpendicular to the flow.

The temperature gradually increases along the direction of fluid flow, which determines the nonuniformity of temperature of the whole bottom plate. This non-uniformity can also be shown by the temperature field of the XZ-section. The average temperature increases almost linear along the flow direction, indicating that the difference is not great in heat transfer capacity under this condition. The random structure effectively breaks the formation of a stable boundary layer in the flow direction, and results in stable heat exchange capability.

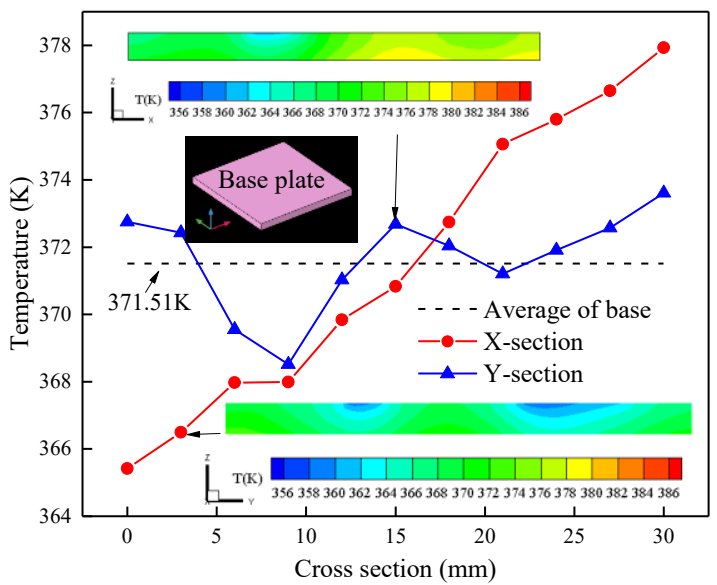

Fig. 4. Average temperature of different sections of the bottom plate $\left(v=1 \times 10^{-2} \mathrm{~m} / \mathrm{s}, \varepsilon=70 \%\right)$. 


\subsection{Field synergy analysis}

The heat transfer intensity at the heat exchange interface depends on the velocity vector field, the temperature gradient vector field, and the angle between them (synergy angle $\Phi$ ) according to the field synergy principle[28, 29]. The smaller the synergy angle, the higher the convective heat transfer intensity.

$$
\phi=\cos ^{-1}\left[\left(u \frac{\partial T}{\partial X}+v \frac{\partial T}{\partial Y}+w \frac{\partial T}{\partial Z}\right) /(|V||\nabla T|)\right]
$$

Fig. 5 shows the isotherm distribution, flow direction and local synergy angle of the fluid at a section, which is $1 \mathrm{~mm}$ away from the bottom plate metal foam. The synergy angle at the edge of skeleton is generally greater than $58^{\circ}$ implying that the boundary layer near by skeleton interfere go against the convective heat transfer process, thereby worsening the heat transfer.

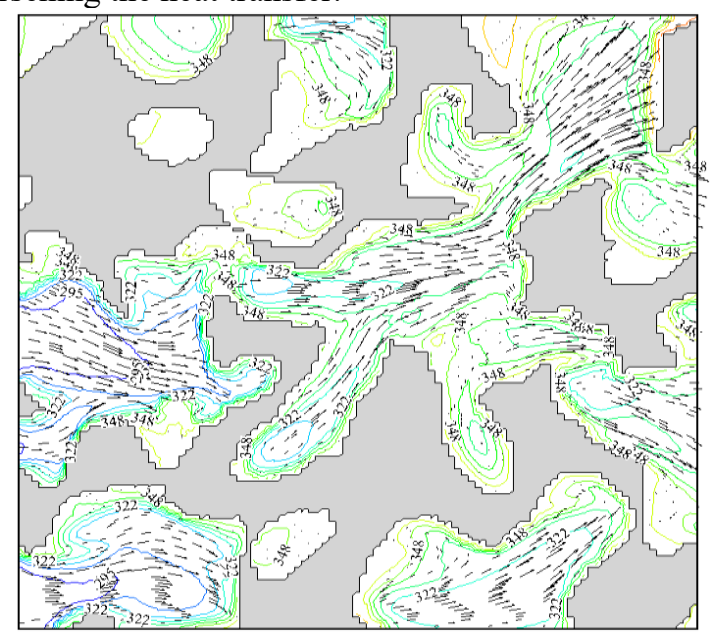

(a) Isotherm distribution and flow direction

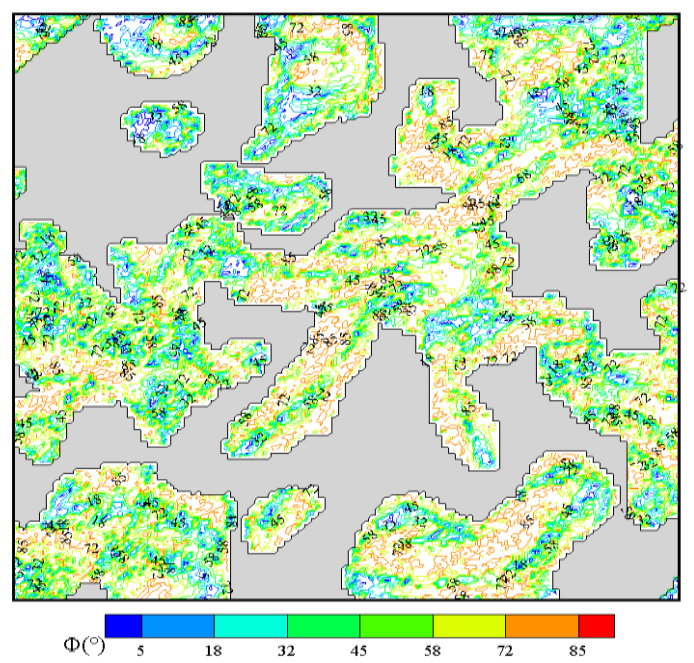

(b) local synergy

Fig. 5. The isotherm distribution, flow direction and local synergy angle of the fluid at $Z=1 \mathrm{~mm}$ section. $\left(v=1 \times 10^{-2} \mathrm{~m} / \mathrm{s}\right.$, $\varepsilon=70 \%)$.

\subsection{Uniformity of base plate temperature}

Two indexes are used to evaluate the temperature uniformity of the bottom plate, which can present the heat transfer characteristics of foam metal. One index $\eta$ is defined as formula (8), which reflects the relative relationship between the maximum and the minimum temperature. The other $\psi$ is defined by formula (9) as the ratio of the standard deviation to the average value of the temperature, which reflect the dispersion degree of each sample point (mesh nodes).

$$
\begin{gathered}
\eta=\frac{T_{\min }}{T_{\max }} \\
\Psi=\frac{\sigma}{\bar{T}}
\end{gathered}
$$

As shown in Fig. 6, low porosity is more favorable for uniformity of the temperature of the bottom plate at low inlet flow rate, but porosity of $50 \%$ and $70 \%$ have better uniformity at higher inlet velocities.
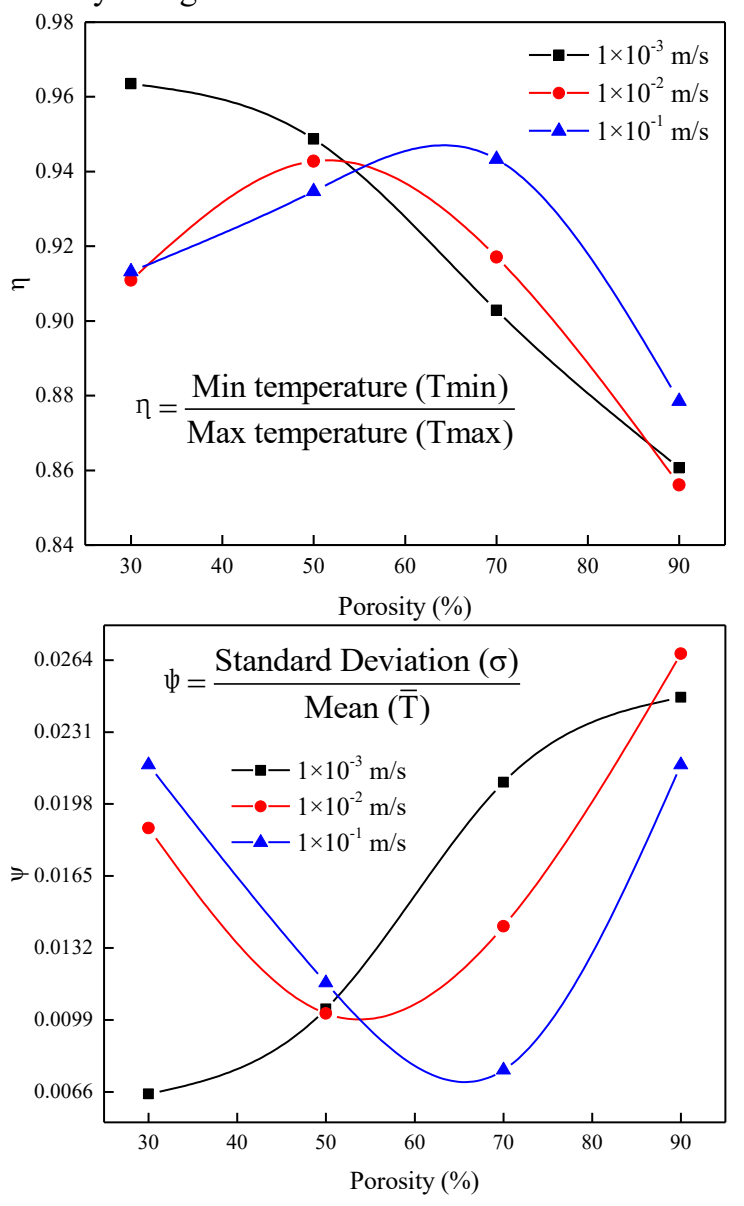

Fig. 6. Substrate temperature uniformity index $\eta$ and $\psi$.

\subsection{Comprehensive performance evaluation}

An evaluation index $\beta$ is used as a criterion for optimizing the foam structure, which defines the relative magnitude of heat transfer and pressure drop.

$$
\beta=h /(\Delta p)^{(1 / 3)}
$$

Fig. 7 shows the relationship between the evaluation index $\beta$ and the porosity at different flow rates. The 
porosity of $30 \%$ has a large convective heat transfer coefficient, but its $\beta$ value is the lowest due to the larger pressure drop. The optimal porosity is $57 \%, 66 \%$ and $76 \%$ at inlet flow rates of $0.001 \mathrm{~m} / \mathrm{s}, 0.01 \mathrm{~m} / \mathrm{s}$, and $0.1 \mathrm{~m} / \mathrm{s}$, respectively. It can be found that the bending degree of the $\beta$ curve gradually decreases as the velocity increases, and the peak gradually shifts to the right. Therefore, the optimal porosity will become larger when the flow velocity increases to a certain value, and the pressure drop will play a major role compared to the heat exchange capability.

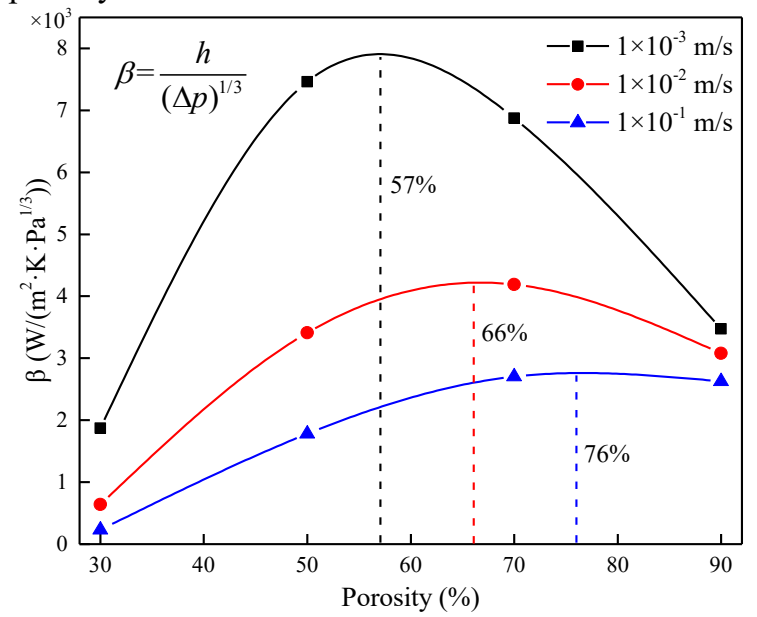

Fig. 7. The change of evaluation index $\beta$ with porosity $\varepsilon$.

\section{Conclusions}

The heat transfer, temperature uniformity of the bottom plate, resistance and field synergy degree inside metal foams was simulated by finite element method in this study. The results show that the foam metal has better heat exchange capacity at higher inlet flow rate, and the boundary layer can develop well along the flow direction. The open-cell foam metal structure has a uniform heat transfer perpendicular to the flow direction. The bottom plate temperature of the low-porosity structure is more uniform at low flow rates. The intermediate porosities $(50 \%$ and $70 \%)$ at high flow rates has a higher uniformity. As the porosity decreases, the internal pressure increases significantly and the pressure loss also becomes significantly larger. The corresponding optimal porosity is $57 \%, 66 \%$ and $76 \%$ at inlet flow rates of $0.001 \mathrm{~m} / \mathrm{s}, 0.01$ $\mathrm{m} / \mathrm{s}$ and $0.1 \mathrm{~m} / \mathrm{s}$, respectively.

The boundary layer at more regions inside foam metal was destructed, resulting in an increase of the overall heat exchange capacity. The increased porosity reduces the synergy degree between the flow field and the temperature field, and the heat exchange gradually deteriorates.

This work was financially supported by the Tianjin Natural Science Foundation (18JCQNJC84600), Foundation of Tianjin Educational Committee (2017KJ177) and Program for
Innovation Research Team of Tianjin Colleges and Universities (TD13-5088).

\section{REFERENCES}

1.Santamouris, M. and D. Kolokotsa, Advanced Environmental Wind Engineering, 2016.

2. Rohsenow, et al., Handbook of Heat Transfer. 1973.

3. Azzi, B. and W. Elias, Animal Reproduction Science, 97(3-4): 334-43 (2004).

4. Lu, T.J., H.A. Stone, and M.F. Ashby, Acta Materialia, 46(10): 3619-3635 (1998).

5. Sharafat, S., et al., Fusion Technology, 39(2): 863867(2001).

6. Ebara, S., S. Toda, and H. Hashizume, Heat and Mass Transfer, 36(4): 273-276(2000).

7. Zumbrunnen, D.A., R. Viskanta, and F.P. Incropera, International Journal of Heat and Mass Transfer, 29(2): 275-284 (1986).

8. Bhattacharya, A. and R.L. Mahajan, Journal of Electronic Packaging, 124(3): 155-163(2002).

9. Rachedi, R. and S. Chikh, Heat and Mass Transfer, 37(4): 371-378(2001).

10. Antohe, B.V., et al., International Journal of Heat and Fluid Flow, 17(6): 594-603(1996).

11. Medraj, M., et al., The effect of microstructure on the permeability of metallic foams. Journal of Materials Science, 42(12): 4372-4383(2007).

12. Wang, H. and L. Guo, Chemical Engineering Science, 155: 438-448(2016).

13. Bamorovat Abadi, G., C. Moon, and K.C. Kim, International Journal of Heat and Mass Transfer, 98: 868-878(2016).

14. Dukhan, N., R.N. PicóN-Feliciano, and A.N.R. ÁLvarez-HernáNdez, Journal of Fluids Engineering, 128(5): 1004-1012(2006).

15. Duursma, G., et al., Heat Transfer Engineering, 36(14-15): 1252-1265(2015).

16. Hristov, Y., et al., Heat and Mass Transfer, 45(7): 999-1017(2009).

17. Nazari, M., et al., International Journal of Thermal Sciences, 88: 33-39(2015).

18. MANCIN, et al., Heat Transfer Performance of Aluminum Foams. Journal of Heat Transfer, 2011. 133(6): p. 060904.

19. Mancin, S., et al., Experimental Thermal and Fluid Science, 36: 224-232(2012).

20. Al-Athel, K.S., et al., International Journal of Thermal Sciences, 116: 199-213(2017).

21. Lu, W., C.Y. Zhao, and S.A. Tassou, International Journal of Heat and Mass Transfer, 49(15): 27512761(2006). 
22. Mahjoob, S. and K. Vafai, International Journal of Heat and Mass Transfer, 51(15): 3701-3711(2008).

23. Kim, S.Y., J.W. Paek, and B.H. Kang, Journal of Heat Transfer, 122(3): 572-578(2000).

24. Kim, S.Y., B.H. Kang, and J.-H. Kim, International Journal of Heat and Mass Transfer, 44(7): 14511454(2001).

25. Coquard, R., D. Rochais, and D. Baillis, Fire Technology, 48(3): 699-732(2012).

26. Batchelor, C.K. and G. Batchelor, An introduction to fluid dynamics, 2000.

27. Hauke, G., An introduction to fluid mechanics and transport phenomena. 86(2008).

28. Tao, W.-Q., Z.-Y. Guo, and B.-X. Wang, International Journal of Heat and Mass Transfer, 45(18): 3849-3856(2002).

29. Chen, Q., J. Ren, and Z. Guo, Chinese Science Bulletin, 53(11): 1768-1772(2008). 